\title{
CRESCIMENTO DE SOJA EM SOLOS EM RESPOSTA A DOSES DE BORO, CALAGEM E TEXTURA DO SOLO
}

\author{
Soybean growth in response to boron dosages, liming and soil texture
}

\author{
Rodinei Facco Pegoraro ${ }^{1}$, José Augusto dos Santos Neto², Ivo Ribeiro da Silva ${ }^{3}$, Renildes Lúcio Ferreira Fontes ${ }^{3}$, \\ Arlindo Ferreira de Faria ${ }^{4}$, Frederico Fonseca Moreira ${ }^{4}$
}

\begin{abstract}
RESUMO
Neste trabalho, objetivou-se quantificar a produção de matéria seca e os conteúdos de B, Ca e Mg na cultura da soja cultivada em solos com diferentes texturas que receberam doses crescentes de B e calagem, e correlacionar o conteúdo de B absorvido pela planta com o teor de $\mathrm{B}$ recuperado com água e $\mathrm{CaCl}_{2}$ ferventes sob influência de doses de boro e a calagem aplicadas em três solos distintos. $\mathrm{O}$ experimento foi conduzido em casa de vegetação em esquema fatorial 3 × 2 x 6, consistindo de três solos: textura arenosa (RQ), textura média (LVA $)$ e textura argilosa $\left(\mathrm{LVA}_{2}\right)$, com e sem calagem, e seis doses de $\mathrm{B}\left(0 ; 1,5 ; 3 ; 6 ; 9\right.$ e $\left.15 \mathrm{mg} \mathrm{dm}^{-3}\right)$, em blocos casualizados com três repetições. Determinou-se o teor de $\mathrm{B}$ no solo extraível com água e $\mathrm{CaCl}_{2}$ ferventes após 45 dias da adição das doses de $\mathrm{B}$ aos solos, massa de matéria seca da parte aérea e os teores de B, Ca e Mg na soja. Ôs teores de B recuperado, tanto pela água fervente, quanto pelo $\mathrm{CaCl}_{2}$ fervente foram semelhantes nos três solos estudados e, apresentaram altas correlações com o conteúdo de B e o peso de matéria seca. As doses de B adicionadas aumentaram a sua absorção pelas plantas, mas causaram redução na produção de matéria seca da parte aérea nos solos RQ (textura arenosa), LVA (textura média) e o LVA (textura argilosa) com calagem, neste último solo, o efeito é minimizado na presença de maior teor de argila.
\end{abstract}

Termos para indexação: Glycine max L., teor de B, água fervente, $\mathrm{CaCl}_{2}$ fervente.

\section{ABSTRACT}

This work aimed to quantify the dry matter production and the contents of B, Ca and $\mathrm{Mg}$ in soybean plants grown in soils with different textures, which received increasing doses of B, and liming. Additionally, it was correlated the B contents in the plants with the $\mathrm{B}$ recovered from the soil with boiling water and $\mathrm{CaCl}_{2}$. The experiment was carried out in a greenhouse in a factorial $3 \times 2 \times 6$ (three soils: sand texture (RQ), loamy sand (LVA) and clayey (LVA) textures; with and without liming; and six B doses: $0 ; 1,5 ; 3 ; 6 ; 9$ and $15 \mathrm{mg} \mathrm{dm}$ ${ }^{3}$ ) arranged in a entirely randomized block design with three replications. It was determined the soil B extracted with boiling water and $\mathrm{CaCl}_{2} 45$ days after the addition of the $\mathrm{B}$ doses to the soil. The shoots dry matter weight and theer $\mathrm{B}$ contents in the soybean plants were determined. The mean concentrations of $\mathrm{B}$ recovered by both boiling water and boiling $\mathrm{CaCl}_{2}$ were similar for the three soils and were highly correlated with the $\mathrm{B}$ contents in the plants and with the dry matter production. The $\mathrm{B}$ doses added increased $\mathrm{B}$ concentration in the plants, but they decreased dry matter production in the RQ soil, and in the LVA and LVA soils with liming. The detrimental effect of high $\mathrm{B}$ in the dry matter production was lowered in the soils with higher clay and organic matter concentrations.

Index terms: Glycine max L., B concentration, boiling water, boiling $\mathrm{CaCl}_{2}$.

(Recebido em 28 de abril de 2006 e aprovado em 17 de janeiro de 2007)

\section{INTRODUÇÃo}

O boro destaca-se por desempenhar importante papel no transporte de açúcares, no metabolismo de carboidratos, na respiração, na síntese e estruturação de células guarda, lignificação e metabolismo de RNA, fenóis e ácido indol acético (AIA) (MARSCHNER, 1995; ROMHELD \& MARSCHNER, 1991). A disponibilidade do nutriente $(\mathrm{B})$ às plantas está associada às propriedades físicas e químicas do solo, como: $\mathrm{pH}$, textura, mineralogia e matéria orgânica (GOLDBERG, 1997; NABLE et al., 1997).
Respostas à aplicação de boro em algumas culturas anuais foram observadas por vários pesquisadores (BUZETTI et al., 1990; DELL \& HUANG, 1997; FERREIRA et al., 2001a; GALRÃO, 1990; GHANATI et al., 2005; RERKASEM et al., 1997; RERKASEM \& JAMJOD, 1997). Entretanto, existem muitas controvérsias entre os resultados, principalmente, pela grande variabilidade das condições físicas e químicas dos solos cultivados e, das necessidades nutricionais das culturas.

A soja é uma das culturas anuais mais exigentes em B, sendo comum a deficiência nessa cultura (FURLANI et

\footnotetext{
Engenheiro Agrônoimo, Doutor - Departamento de Ciências Agrárias - Universidade Estadual de Montes Claros - Avenida Reinaldo Viana, 2630 , Bico da Pedra- Cx.P. 91 - 39440-000 - Janaúba, MG - rodinei_pegoraro@yahoo.com.br

${ }^{2}$ Engenheiro Agrônomo, Mestre - Departamento de Ciências Agrárias - Universidade Estadual de Montes Claros - Avenida Reinaldo Viana, 2630 , Bico da Pedra - Cx. P. 91 - 39440-000 - Janaúba, MG - augustojn@ig.com.br

${ }^{3}$ Doutores - Universidade Federal de Viçosa/UFV - Avenida Ph Holfs s/n - 36570-000 - Viçosa, MG - ivosilva@ufv.com.br; renildes@ufv.br ${ }^{4}$ Engenheiros Agrônomos - Universidade Federal de Viçosa/UFV - Avenida Ph Holfs s/n - 36570-000 - Viçosa, MG - arlindofaria@vicosa.ufv.br; frediffm@bol.com.br
} 
al., 2001), bem como, é também bastante sensível a sua toxidez (ROSOLEM, 1980). A deficiência é constatada quando o teor foliar é inferior a 25 a $30 \mathrm{mg} \mathrm{kg}^{-1}$, e a toxidez aparece para teor acima de $83 \mathrm{mg} \mathrm{kg}^{-1}$, dependendo da cultivar e das condições do ambiente (FURLANI et al., 2001).

O método de rotina para determinação do teor de $\mathrm{B}$ disponível nos solos dos Estados de Minas Gerais e Bahia é o da extração com água fervente (ALVAREZ et al., 1999). Entretanto, por se tratar de um procedimento demorado e de alto custo, têm sido realizados estudos com outros extratores, como, por exemplo, $\mathrm{CaCl}_{2}$, por ser facilmente executado e apresentar resultados semelhantes aos obtidos com água fervente (BATAGLIA \& RAIJ, 1990; FERREIRA et al., 2001a).

A disponibilidade de B para as plantas é afetada por vários fatores como o teor de argila, minerais da fração argila e pH. Ferreira et al. (2001a), em estudo com milho, verificaram que o B aplicado ao solo foi retido em maior quantidade nos solos com altos teores de argila, e que o aumento dos teores de óxidos livres de $\mathrm{Fe}$ afetou a capacidade de recuperação de $\mathrm{B}$ pelos extratores (água fervente e $\mathrm{CaCl}_{2}$ ), comprometendo a avaliação do teor disponível de $\mathrm{B}$.

Objetivou-se com este trabalho avaliar a produção de matéria seca, a concentração de B, Ca e Mg e a correlação entre os nutrientes absorvidos com o teor de $\mathrm{B}$ por meio dos extratores água e $\mathrm{CaCl}_{2}$ ferventes, em relação da textura do solo na ausência ou presença da calagem.

\section{MATERIAL E MÉTODOS}

O experimento foi conduzido em casa de vegetação em esquema fatorial $3 \times 2 \times 6$, constituído por três solos: em relação a textura (arenosa, média e argilosa), com e sem calagem e seis doses de B $\left(0 ; 1,5 ; 3 ; 6 ; 9\right.$ e $\left.15 \mathrm{mg} \mathrm{dm}^{-3}\right)$. Os solos adotados foram classificados como Neossolo Quatzarênico (RQ), textura arenosa, e Latossolos Vermelho Amarelo (LVA, textura média, e LVA, textura argilosa). Utilizou-se o delineamento em blocos casualizados, com três repetições. As amostras de solo foram coletadas na profundidade de $0-20 \mathrm{~cm}$, secadas e peneiradas em peneira com malha de $2 \mathrm{~mm}$ para a análise dos atributos químicos e físicos (Tabela 1).

\section{Determinação do $\mathrm{B}$ disponível por água e $\mathrm{CaCl}_{2}$ ferventes}

As unidades experimentais foram constituídas de sacos plásticos contendo $0,6 \mathrm{dm}^{3}$ de solo. Inicialmente, o $\mathrm{pH}$ dos tratamentos com calagem foi elevado a aproximadamente 6,0, utilizando-se $\mathrm{CaCO}_{3}$ e $\mathrm{MgCO}_{3}$ na proporção de 4:1. A dose do corretivo foi calculada conforme a recomendação de Alvarez \& Ribeiro (1999). Os solos, com e sem calagem, foram incubados em sacos plásticos por 15 dias mantendo a umidade em $80 \%$ da capacidade de campo. Posteriormente, os solos receberam as doses de $\mathrm{B}\left(0 ; 1,5 ; 3 ; 6 ; 9\right.$ e $\left.15 \mathrm{mg} \mathrm{dm}^{-3}\right)$ na forma de $\mathrm{H}_{3} \mathrm{BO}_{3}$ e foram, novamente, incubados por um período de 45 dias. Após esse período, coletaram-se sub-amostras para análises de $\mathrm{pH}$ e determinação dos teores de $\mathrm{B}$ no

Tabela 1 - Atributos químicos e físicos do Neossolo Quartzarênico (RQ), Latossolo Vermelho Amarelo (LVA $)$ e do Latossolo Vermelho Amarelo $\left(\mathrm{LVA}_{2}\right)^{(*)}$.

\begin{tabular}{|c|c|c|c|}
\hline Características & RQ & $\mathrm{LVA}_{1}$ & $\mathrm{LVA}_{2}$ \\
\hline pH água 1:2,5 (antes da calagem) & 4,6 & 4,5 & 4,2 \\
\hline pH água 1:2,5 (após calagem) & 5,8 & 6,0 & 5,5 \\
\hline Mat. orgânica dag kg ${ }^{-1 \#}$ & 1,6 & 1,0 & 7,1 \\
\hline $\mathrm{Ca}^{2+}, \mathrm{cmol}_{\mathrm{c}} \mathrm{dm}^{-3(\S)}$ & 0,3 & 0,2 & 0,1 \\
\hline $\mathrm{Mg}^{2+}, \mathrm{cmol}_{\mathrm{c}} \mathrm{dm}^{-3(\S)}$ & 0,2 & 0,3 & 0,1 \\
\hline $\mathrm{B}, \mathrm{mg} \mathrm{dm}^{-3(ə)}$ & 0,9 & 0,5 & 0,5 \\
\hline $\mathrm{Al}^{3+}, \mathrm{cmol}_{\mathrm{c}} \mathrm{dm}^{-3(\S)}$ & 0,9 & 1,7 & 2,7 \\
\hline Areia, dag $\mathrm{kg}^{-1(\$)}$ & 88,0 & 62,0 & 25,0 \\
\hline Silte, dag kg ${ }^{-1(\$)}$ & 3,0 & 8,0 & 11,0 \\
\hline Argila, dag $\mathrm{kg}^{-1(\$)}$ & 9,0 & 30,0 & 64,0 \\
\hline Densidade aparente, $\mathrm{kg} \mathrm{dm}^{-3(\phi)}$ & 1,4 & 1,3 & 1,1 \\
\hline
\end{tabular}

\#Walkley-Black; ${ }^{(\S)} \mathrm{KCl} 1 \mathrm{~mol} \mathrm{~L}{ }^{-1}$; (Y)(ABREU et al., 1994); ${ }^{(\$)}$ Embrapa (1997); ${ }^{(()}$Método da proveta; ${ }^{(\sharp)}$ Exceto para os valores de $\mathrm{pH}$, todos as demais características se referem aos solos antes da calagem. 
solo extraído com água fervente e $\mathrm{CaCl}_{2}$ fervente $\left(5 \mathrm{mmol} \mathrm{L}^{-1}\right)$, cuja análise foi feita pelo método da azometina-H. Para extração com água e $\mathrm{CaCl}_{2}$ fervente foram utilizados sacos de polietileno $(29,2 \times 14,7 \mathrm{~cm})$. A relação solo:solução foi de 1:2, adicionando-se $0,5 \mathrm{~cm}^{3}$ de carvão ativado. Os sacos perfurados $\mathrm{a} \pm 1 \mathrm{~cm}$ à direita da extremidade superior foram fechados e obtida a massa. Depois, foram aquecidos por meio de forno microondas durante $4 \mathrm{~min}(700 \mathrm{~W})$ e $5 \mathrm{~min}$ (490 W). A massa dos sacos foi corrigida para a inicial, procedendo-se em seguida a filtragem do sobrenadante (FERREIRA et al., 20001b).

\section{Absorção do B pela soja}

Numa segunda etapa, foi cultivada a soja em vasos durante trinta dias, em que as unidades experimentais foram adaptadas da técnica de Neubauer. Nos vasos de plástico foram adicionados $100 \mathrm{~cm}^{3}$ de areia, previamente lavada com ditionito e ácido clorídrico e, sobre esta, adicionaramse $200 \mathrm{~cm}^{3}$ de solo, seguida da adição de mais $200 \mathrm{~cm}^{3}$ de areia. Todos os solos foram adubados com quantidade de nutrientes necessária para cultivo de soja em vaso em casa de vegetação (NOVAIS et al., 1991), exceto para o B. Em cada vaso E cada vaso colocou-se seis sementes de soja, as quais foram desbastadas após a germinação, deixandose quatro plantas por vaso. Objetivou-se com esta técnica cultivar o maior número possível de plantas num pequeno volume de solo, visando extrair uma maior quantidade de $\mathrm{B}$ adicionado ao solo. Com 30 dias de cultivo, as plantas foram colhidas e secadas em estufa com circulação de ar a $72{ }^{\circ} \mathrm{C}$ por 48 horas para determinação da massa de matéria seca e os teores de $\mathrm{B}, \mathrm{Ca}$ e $\mathrm{Mg}$ na parte aérea, após a digestão nitroperclórica. As quantidades de nutrientes foi calculada a partir da matéria seca das plantas e dos teores dos nutrientes.

Os resultados foram submetidos à análise de variância para modelos fatoriais, testando-se as interações entre solos x calagem $\mathrm{x}$ doses de boro e o desdobramento das interações, utilizando o programa estatístico SAEG 6.0 (Sistema de Análises Estatísticas e Genéticas) e, quando pertinente, foi realizada análise de regressão com teste de identidade de modelos para as equações de $\mathrm{B}$ recuperado por água e $\mathrm{CaCl}_{2}$ ferventes (SANTOS NETO, 2003).

\section{RESULTADOS E DISCUSSÃO}

Os teores médios de $\mathrm{B}$ extraídos com água e $\mathrm{CaCl}_{2}$ fervente, com e sem a calagem, variaram de 2,74 a 5,47 mg $\mathrm{dm}^{-3}$ para a água fervente e de 2,39 a 4,39 $\mathrm{mg} \mathrm{dm}^{-3}$ para o $\mathrm{CaCl}_{2}$. As doses adicionadas de $\mathrm{B}$ aumentaram linearmente os teores do nutriente extraído pela água e $\mathrm{CaCl}_{2}$ fervente, entretanto, não se obteve efeito significativo $(\mathrm{P}>5 \%)$ da calagem no teor de $\mathrm{B}$ recuperado com água e $\mathrm{CaCl}_{2}$ ferventes nos três solos, ajustando-se equações lineares entre as medias de teor de B no solo com e sem calagem (Figura 1). Estes resultados indicaram que a água e o $\mathrm{CaCl}_{2}$ ferventes não foram sensíveis à calagem, confirmado pelo teste de identidade de modelos. Já, Alleoni \& Camargo (2000) verificou que a capacidade de adsorção de B em solos corrigidos pela calagem foi maior, o que poderia reduzir a sua capacidade de extração com água e $\mathrm{CaCl}_{2}$ ferventes.

Maiores taxas de recuperação de $\mathrm{B}$ foram obtidas no solo de textura arenosa (Figura 1), onde as doses adicionadas de $\mathrm{B}$ promoveram aumento significativo nos teores do nutriente extraído por água e $\mathrm{CaCl}_{2}$ fervente e, a sua absorção pela soja em todos os solos (Figura 2).

$\mathrm{Na}$ relação entre B recuperado pelos extratores com as doses adicionadas, no solo arenoso (RQ), foi observada uma declividade maior da reta, comparativamente aos outros solos $\left(\mathrm{LAV}_{1}\right.$ e LVA $)$ (Figura 1). Esta observação deve-se a textura mais argilosa dos solos $\mathrm{LVA}_{1}\left(30 \mathrm{dag} \mathrm{kg}^{-1}\right)$ e $\mathrm{LVA}_{2}\left(64 \mathrm{dag} \mathrm{kg}^{-1}\right)$ e, possivelmente, pela maior presença de minerais de caulinita e óxidos (SANTOS NETO, 2003), aumentando a capacidade de adsorção do B adicionado (ALLEONI \& CAMARGO, 2000; GOLDBERG \& GLAUBIG 1985; KEREN \& GAST, 1983). Em decorrência destes fatores, obteve-se menor absorção de B pela soja nos solos com maior teor de argila (Figura 2).

A taxa de recuperação de B na extração feita com água fervente foi superior à da extração com $\mathrm{CaCl}_{2}$, confirmando os resultados de Ferreira et al. (2001a). Estes autores atribuíram a superioridade do $\mathrm{CaCl}_{2}$ fervente à mudança da força iônica da solução extratora que promove um equilíbrio químico entre os íons em solução, elevando o teor de B da mesma.

Mesmo não obtendo-se efeito significativo ( $\mathrm{P}>5 \%$ ) no teor de $\mathrm{B}$ extraído do solo com água e $\mathrm{CaCl}_{2}$ ferventes, a calagem favoreceu o crescimento das plantas e aumentou os teores de B, Ca e Mg (Figura 1). Já com a elevação das doses de B ocorreu redução na produção de matéria seca da parte aérea da soja nos três solos avaliados, na presença da calagem. Este efeito foi menos pronunciado em comparação à determinação feita no solo arenoso. A redução da produção de matéria seca na presença da calagem pode ser justificada pelo efeito tóxico do $\mathrm{B}$ às plantas, uma vez que os teores de $\mathrm{B}$ extraídos com água quente e $\mathrm{CaCl}_{2}$ fervente (Figura 1), nas maiores doses foram superiores ao nível crítico que é, de aproximadamente, 0,6 $\mathrm{mg} \mathrm{dm}^{-3}$ (solo) (ALVAREZ et al., 1999), ou 20 a $55 \mathrm{mg} \mathrm{kg}^{-1}$ (PAULETTI, 1998). As correlações negativas entre o teor de B na planta e produção de matéria seca, especialmente nos solos mais arenosos (Tabela 2) justificam esta afirmação. 


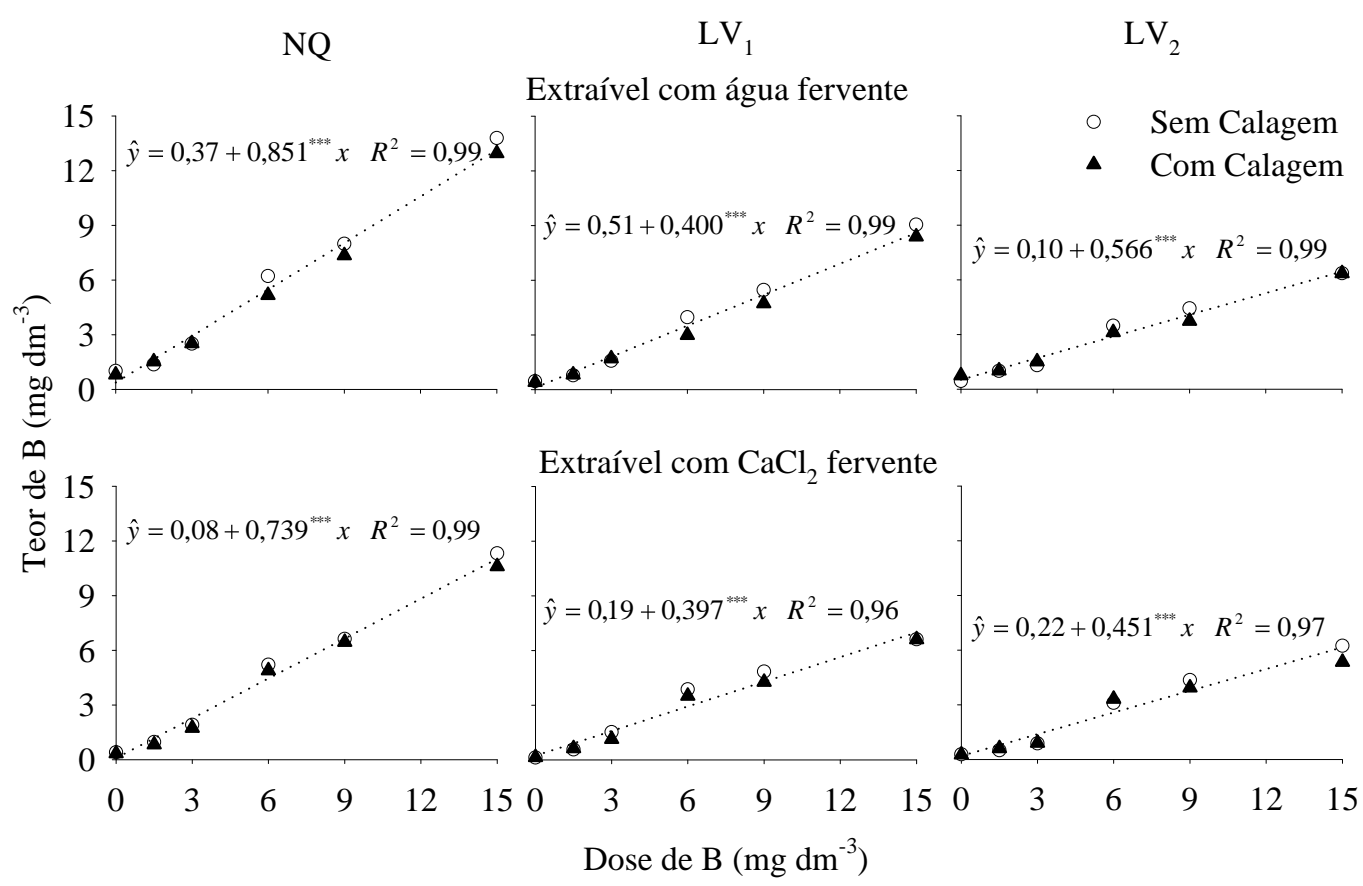

Figura 1 - Teores de $\mathrm{B}$ recuperado pelos extratores água fervente e $\mathrm{CaCl}_{2}$ fervente após a adição de doses de $\mathrm{B}$ em Neossolo Quartzarênico (RQ, textura arenosa), no Latossolo Vermelho Amarelo (LVA, textura média) e no Latossolo Vermelho Amarelo (LVA 2 , textura argilosa), na ausência e na presença da calagem. ***: $0,1 \%$ de significância $(\mathrm{P}<5 \%)$.

A maior toxidez de B na presença da calagem pode estar associada à excessiva disponibilidade para as plantas. De acordo com Furlani et al. (2001), as cultivares de soja começam a sofrer problemas de toxidez, quando possuem teores da ordem de $83 \mathrm{mg} \mathrm{kg}^{-1}$, como observado no presente estudo, principalmente, nas maiores aplicações de B nos solos de textura arenosa e média.

Nos tratamentos sem calagem nos solos LVA $_{1}$ e $\mathrm{LVA}_{2}$ (Figura 2) verificou-se que a produção de matéria seca foi semelhante em todas as doses de B aplicadas ao solo. Possivelmente, os menores valores de $\mathrm{pH}$ reduziram a disponibilidade de $\mathrm{B}$ no solo às plantas. Os principais fatores limitantes do crescimento da soja e da absorção de $\mathrm{B}$ nesta condição, provavelmente, sejam os baixos teores de $\mathrm{Ca}$ e $\mathrm{Mg}$, e os teores tóxicos de $\mathrm{Al}^{3+}$ (Tabela 1), pois os teores recuperados de $\mathrm{B}$, com e sem calagem, foram semelhantes. Assim, pode-se afirmar que o fornecimento de B só deve ser realizado em solos corrigidos, para eliminar os efeitos tóxicos de $\mathrm{Al}$ e ter um suprimento adequado de $\mathrm{Ca}$ e $\mathrm{Mg}$.

A absorção de B pelas plantas de soja esteve associada às taxas de recuperação obtidas para cada solo, ou seja, no solo arenoso as taxas de recuperação pelos extratores foram maiores e a planta apresentou maior teor desse nutriente, seguido do solo de textura média e textura argilosa. Esta afirmação fundamentea-se nos altas correlações positivas entre as taxas de recuperação dos extratores e os teores de B nas plantas (Tabela 2).

As menores taxas de recuperação de $\mathrm{B}$ do solo e dos teores de B absorvidos pelas plantas foram encontrados no solo argiloso, fato que pode ser explicado pelo maior teor de matéria orgânica $\left(7,1 \mathrm{dag} \mathrm{kg}^{-1}\right) \mathrm{e}$ formação de compostos menos solúveis com os ligantes orgânicos (MALAVOLTA, 1980), bem como, por causa da mineralogia caulinítica e presença de óxidos (SANTOS NETO, 2003).

Os teores de B extraídos do solo pelos extratores (água e $\mathrm{CaCl}_{2}$ fervente) estudados apresentaram correlações altamente significativas e positivas com os teores de B absorvidos pelas plantas, com ou sem calagem (Tabela 2). As correlações negativas observadas para o crescimento da parte aérea, possivelmente, resultou de toxidez de B. Essas correlações foram menores nos solos de texturas argilosa e média, justamente onde o decréscimo de crescimento foi menor, devido ao aumento das doses de B aplicadas no solo. 

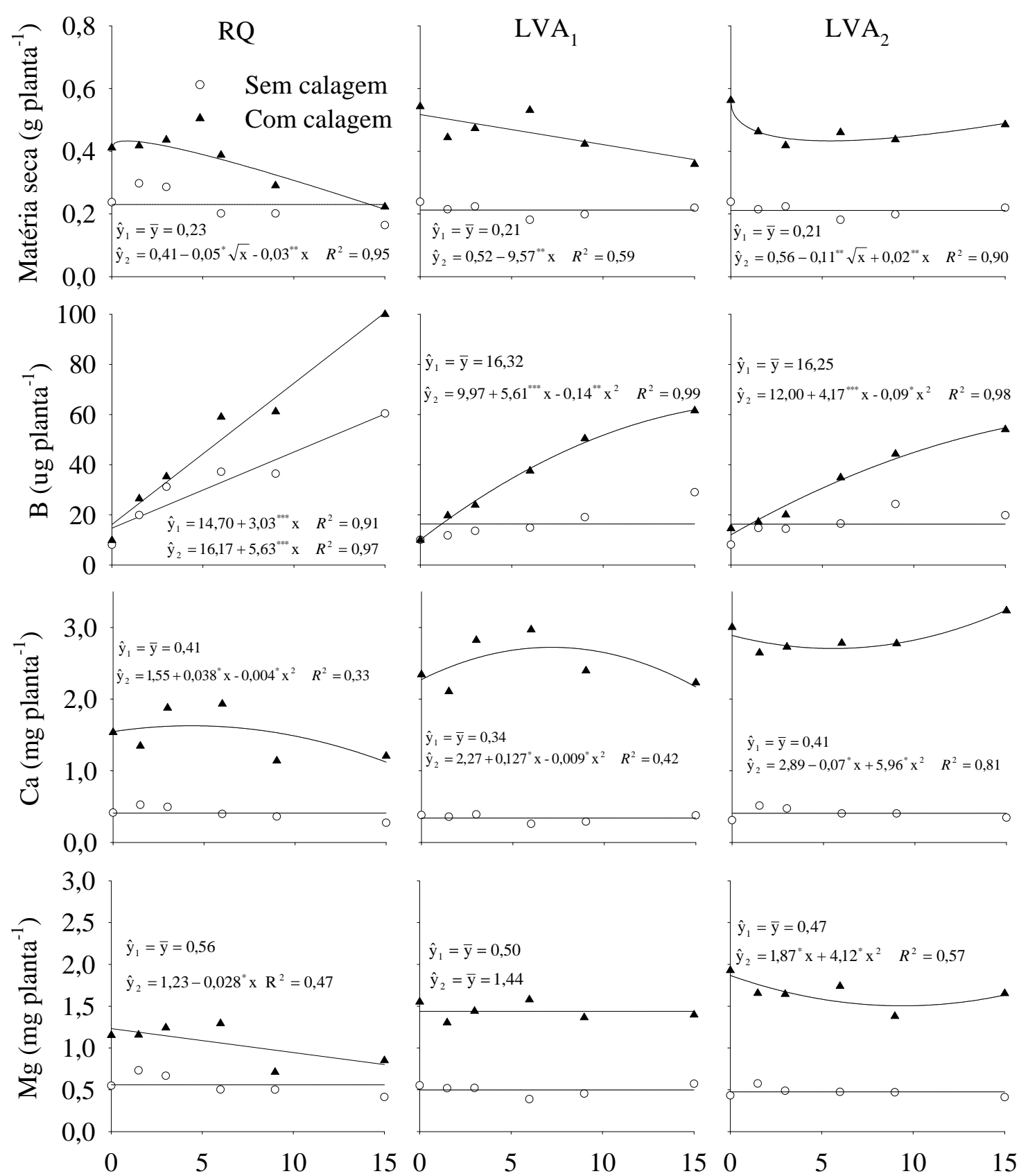

Dose de Boro $\left(\mathrm{mg} \mathrm{dm}^{-3}\right)$

Figura 2 - Matéria seca da parte aérea de soja $\left(\mathrm{g} \mathrm{planta}^{-1}\right)$, teores de B ( $\left.\mu \mathrm{g} \mathrm{planta}^{-1}\right), \mathrm{Ca}$ e $\mathrm{Mg}\left(\mathrm{mg} \mathrm{planta}^{-1}\right)$ influenciados pela adição de doses crescentes de $\mathrm{B}$ em Neossolo Quartzarênico (RQ, textura arenosa), no Latossolo Vermelho Amarelo (LVA, textura média) e no Latossolo Vermelho Amarelo (LVA 2 , textura argilosa), na ausência e na presença da calagem. $* * *: 0,1 \%$ de significância $(\mathrm{P}<5 \%)$. 
Tabela 2 - Coeficientes de correlação linear (Pearson) entre a matéria seca (MS) e o teor de B na planta comparados aos teores de $\mathrm{B}$ dos solos extraídos com água e $\mathrm{CaCl}_{2}$ ferventes, na ausência e presença da calagem.

\begin{tabular}{|c|c|c|c|c|c|c|c|c|c|}
\hline & \multicolumn{9}{|c|}{ Sem calagem } \\
\hline & \multicolumn{3}{|c|}{ NQ } & \multicolumn{3}{|c|}{$\mathrm{LVA}_{1}$} & \multicolumn{3}{|c|}{$\mathrm{LVA}_{2}$} \\
\hline & B & MS & Água & B & MS & Água & B & MS & Água \\
\hline MS & $-0,68^{\text {ns }}$ & & & $-0,15^{\text {ns }}$ & & & $-0,25^{\mathrm{ns}}$ & & \\
\hline Água & $0,94^{* *}$ & $-0,87^{*}$ & & $0,98^{* * * *}$ & $-0,33^{\text {ns }}$ & & $0,80^{*}$ & $-0,62^{\mathrm{ns}}$ & \\
\hline $\mathrm{CaCl}_{2}$ & $0,94^{* *}$ & $-0,86^{*}$ & $1,00^{* * * *}$ & $0,93^{* *}$ & $-0,48^{\text {ns }}$ & $0,98^{* * *}$ & $0,79^{*}$ & $-0,66^{\text {ns }}$ & $1,00^{* * * *}$ \\
\hline
\end{tabular}

\begin{tabular}{|c|c|c|c|c|c|c|c|c|c|}
\hline & \multicolumn{9}{|c|}{ Com calagem } \\
\hline & \multicolumn{3}{|c|}{ NQ } & \multicolumn{3}{|c|}{$\mathrm{LVA}_{1}$} & \multicolumn{3}{|c|}{$\mathrm{LVA}_{2}$} \\
\hline & B & MS & Água & $\mathrm{B}$ & MS & Água & B & MS & Água \\
\hline MS & $-0,80^{*}$ & & & $-0,74^{*}$ & & & $-0,24^{\mathrm{ns}}$ & & \\
\hline Água & $0,98^{* * * * *}$ & $-0,87^{*}$ & & $0,96^{* * * *}$ & $-0,78^{*}$ & & $0,98^{* * * *}$ & $-0,17^{\mathrm{ns}}$ & \\
\hline $\mathrm{CaCl}_{2}$ & $0,98^{* * * *}$ & $-0,88^{*}$ & $0,99^{* * *}$ & $0,98^{* * * *}$ & $-0,68^{\mathrm{ns}}$ & $0,98^{* * * *}$ & $0,99^{* * *}$ & $-0,23^{\mathrm{ns}}$ & $0,98^{* * * *}$ \\
\hline
\end{tabular}

ns, *, ** e ***: não significativo ( $P>5 \%$ ), significativo a 5,1 e $0,1 \%$, respectivamente. RQ-textura arenosa, $\mathrm{LVA}_{1}$-textura média e $\mathrm{LVA}_{2}$-textura argilosa.

\section{CONCLUSÕES}

Os teores de B recuperados pelos extratores água e $\mathrm{CaCl}_{2}$ fervente são semelhantes, independentemente das texturas dos solos, com boa eficiência para a estimativa do teor de $\mathrm{B}$ disponível à soja, nestas condições de cultivo. A adição de doses de $\mathrm{B}$, a partir de $1,5 \mathrm{mg} \mathrm{dm}^{-3}$, aumenta a sua absorção pelas plantas, mas causa redução na produção de matéria seca da parte aérea nos solos RQ (textura arenosa), $\mathrm{LVA}_{1}$ (textura média) e o LVA (textura argilosa) com a calagem, cujo efeito é minimizado na presença de maior teor de argila.

\section{REFERÊNCIAS BIBLIOGRÁFICAS}

ABREU, C. A.; ABREU, M. F.; RAIJ, B. van; BATAGLIA, O. C. Extraction of boron from soil by microwave heating for ICP-AES determination. Communications in Soil Science and Plant Analysis, New York, v. 25, n. 18/20, p. 3321-3333, 1994.

ALLEONI, L. R. F.; CAMARGO, O. A. Boron adsorption in soils from the state of São Paulo, Brasil. Pesquisa Agropecuária Brasileira, Brasília, v. 35, n. 2, p. 413-421, 2000.

ALVAREZ, V. H.; NOVAIS, R. F.; BARROS, N. F.; CANTARUTTI, R. B.; LOPES, A. S. Interpretação dos resultados das análises de solos. In: RIBEIRO, A. C.; GUIMARÃES, P. T. G.; ALVAREZ, V. H. (Eds.). Recomendação para o uso de corretivos e fertilizantes em Minas Gerais: $5^{a}$ aproximação. Viçosa: CFSEMG, 1999. p. 25-32.
ALVAREZ, V. H.; RIBEIRO, A. C. Calagem. In: RIBEIRO, A. C.; GUIMARÃES, P. T. G.; ALVAREZ, V. H. (Eds.). Recomendação para o uso de corretivos e fertilizantes em Minas Gerais: $5^{a}$ aproximação. Viçosa: CFSEMG, 1999. p. 43-60.

BATAGLIA, O. C.; RAIJ, B. van. Eficiência de extratores na determinação de boro em solos. Revista Brasileira de Ciência do Solo, Campinas, v. 14, n. 1, p. 25-31, 1990.

BUZETTI, S.; MURAOKA, T.; SÁ, M. E. Doses de boro na soja, em diferentes condições de acidez do solo: I. produção de matéria seca e de grãos e nível crítico no solo. Revista Brasileira de Ciência do Solo, Campinas, v. 14, n. 2, p. 157-161, 1990.

DELL, B.; HUANG, L. B. Physiological response of plants to low boron. Plant and Soil, Dordrecht, v. 193, n. 1/2, p. 103-120, 1997.

EMPRESA BRASILEIRA DE PESQUISA AGROPECUÁRIA. Centro Nacional de Pesquisa de Solos. Manual de métodos de análise de solo. 2. ed. Rio de Janeiro: Ministério da Agricultura e do Abastecimento, 1997. $212 \mathrm{p}$.

FERREIRA, G. B.; FONTES, R. L. F.; FONTES, M. P. F.; ALVAREZ, V. H. Influência de algumas características do solo nos teores de boro disponível. Revista Brasileira de Ciência do Solo, Viçosa, v. 25, n. 1, p. 91-101, 2001a. 
FERREIRA, G. B.; FONTES, R. L. F.; FONTES, M. P. F.; ALVAREZ, V. H. Comparing calcium chloride, barium chloride, and hot waters extractions and testing activated charcoal plus azomethine-H dosage for boron determination in Brasilian soils. Communications in Soil Science and Plant Analysis, New York, v. 32, n. 19/20, p. 3153-3167, 2001b.

FURLANI, A. M. C.; TANAKA, R. T.; TARALLO, M.; VERDIAL, M. F.; MASCARENHAS, H. A. A. Exigência a boro em cultivares de soja. Revista Brasileira de Ciência do Solo, Campinas, v. 25, n. 4, p. 929-937, 2001.

GALRÃO, E. Z. Effect of micronutrients and liming on the yield of soybeans grown in a lowland meadow soil. Revista Brasileira de Ciência do Solo, Campinas, v. 14, n. 3, p. 381384, 1990.

GHANATI, F.; MORITA, A.; YOKOTA, H. Deposition of suberin in roots of soybean induced by excess boron. Plant Science, Shannon, v. 168, p. 397-405, 2005.

GOLDBERG, S.; GLAUBIG, R. A. Boron adsorption on aluminum and iron oxide minerals. Soil Science Society of Amerina Journal, Madison, v. 49, n. 6, p. 1374-1379, 1985.

GOLDBERG, S. Reactions of boron with soils. Plant and Soil, Dordrecht, v. 193, n. 1/2, p. 35-48, 1997.

KEREN, R.; GAST, R. G. Ph-dependent boron adsorption by montmorillonite hidroxi-aluminum complexes. Soil Science Society of Amerina Journal, Madison, v. 47, n. 6, p, 1116-1121, 1983.

MALAVOLTA, E. Elementos de nutrição mineral de plantas. Piracicaba: Agronômica Ceres, 1980. 251 p.
MARSCHNER, H. Mineral nutrition of higher plants. 2. ed. San Diego: Academic, 1995. 889 p.

NABLE, R. O.; BAÑUELOS, G. S.; PAULL, J. G. Boron toxicity. Plant and Soil, Dordrecht, v. 193, n. 1/2, p. 181198, 1997.

NOVAIS, R. F.; NEVES, J. C. N.; BARROS, N. F. Ensaio em ambiente controlado. In: EMPRESA BRASILERIA DE PESQUISA AGROPECUÁRIA. Métodos de pesquisa em fertilidade do solo. Brasília, DF, 1991. p. 189-253.

PAULETTI, V. Nutrientes: teores e interpretações. Campinas: Fundação ABC/Fundação Cargil, 1998. 59 p.

RERKASEM, B.; BELL, R. W.; LODKAEW, S.; LONERAGAN, J. F. Relationship of seed boron concentration to germination and growth of soybean (Glycine max). Nutrient Cycling in Agroecosystems, [S.1.], v. 48, n. 3, p. 217-223, 1997.

RERKASEM, B.; JAMJOD, S. Genotypic variation in plant response to low boron and implications for plant breeding. Plant and Soil, Dordrecht, v. 193, n. 1/2, p. 169-180, 1997.

ROMHELD, V.; MARSCHNER, H. Function of micronutrients in plants. In: MORTVEDT, J. J.; COX, F. R.; SHUMAN, L. M.; WELCH, R. M. (Eds.). Micronutrients in agriculture. Madison: SSSA, 1991. p. 297-328.

ROSOLEM, C. A. Nutrição mineral e adubação de soja. Piracicaba: Instituto da Potassa, 1980. 80 p. (Boletim técnico, 6).

SANTOS NETO, J. A. Taxas de recuperação de zinco, cobre e boro por diferentes extratores em solos da Bahia e de Minas Gerais. 2003. 51 f. Dissertação (Mestrado em Solos e Nutrição de Plantas) - Universidade Federal de Viçosa, Viçosa, 2003. 